\title{
Study of the external female genitalia of 14 Rhodnius species (Hemiptera, Reduviidae, Triatominae) using scanning electron microscopy
}

\author{
João Aristeu da Rosa ${ }^{1 *}$, Vagner José Mendonça ${ }^{1 \dagger}$, Sueli Gardim ${ }^{1 \dagger}$, Danila Blanco de Carvalho ${ }^{1 \dagger}$, Jader de Oliveira ${ }^{1 \dagger}$, \\ Juliana Damieli Nascimento ${ }^{2 \dagger}$, Heloisa Pinotti ${ }^{3 \dagger}$, Mara Cristina Pinto ${ }^{1 \dagger}$, Mario Cilense ${ }^{4 \dagger}$, Cleber Galvão ${ }^{5 \dagger}$ \\ and José Maria Soares Barata ${ }^{6 \dagger}$
}

\begin{abstract}
Background: Among the vectors of Chagas disease (Hemiptera: Reduviidae:Triatominae), there are eighteen Rhodnius species described and some are difficult to identify. The aim of this article is to contribute to the specific identification of fourteen Rhodnius spp. through morphological characters of the external female genitalia.

Methods: Female abdomens were cut transversely. The specimens were then prepared for examination by using scanning electron microscopy.

Results: The careful examination of the dorsal, posterior and ventral sides revealed characteristics that allowed the identification of each of the fourteen species.

Conclusion: The use of external female genitalia as characteristics are proposed as a tool for specifically identifying Rhodnius species, and an identification key for these species is presented.
\end{abstract}

Keywords: Triatominae, Rhodnius, External female genitalia, Scanning electron microscopy

\section{Background}

The Triatominae subfamily is a fundamental link in the epidemiological chain of the protozoan Trypanosoma cruzi, which is a registered parasite for 24 families and 150 mammalian species as well as humans [1]. Among the 18 genera comprised in the Triatominae subfamily $[2,3]$, Rhodnius has been the most difficult to specifically identify according to studies by Neiva and Pinto [4]; Lent et al. [5], Bérenger and Sigwalt [6]. Rhodnius species can infect by $T$. rangeli too [7].

The first two species described for the genus Rhodnius were $R$. nasutus and $R$. prolixus, which were described in 1859 [8]; between that year and 1979, 10 more species were added to this genus [9]. In 2003, 4 species were added to this genus [2] by rehabilitation of $R$. amazonicus [6], description of $R$. stali [5], R. colombiensis [10],

\footnotetext{
* Correspondence: joaoaristeu@gmail.com

${ }^{\dagger}$ Equal contributors

'Departamento de Ciências Biológicas, Faculdade de Ciências Farmacêuticas, Universidade Estadual Paulista, Rodovia Araraquara-Jaú km 1, 14 801-902,

Araraquara, SP, Brasil

Full list of author information is available at the end of the article
}

and $R$. milesi [11]. The seventeenth and eighteenth species described for this genus were $R$. zeledoni [12] and $R$. montenegrensis [13].

Based on the literature, identifying such vectors still relies on morphological characteristic descriptions [5,10], even though genotype studies have improved significantly and now contribute to phylogenetic evaluations [14-16].

External female genitalia from the Triatominae subfamily have rarely been used to characterize triatomines $[6,17]$ compared with male genitalia, which have been frequently used as one of the main taxonomic characteristics $[5,12,18]$. After studying external female genitalia from Panstrongylus herreri, P. megistus, R. colombiensis, $R$. prolixus, Triatoma infestans and $T$. vitticeps through scanning electron microscopy (SEM), Rosa et al. [19] validated this morphology for taxonomy.

Among species of Rhodnius such as $R$. brethesi and $R$. pictipes there is no difficultly in identification [9]. However, other species such, $R$. nasutus, $R$. neglectus, $R$. prolixus and $R$. robustus, are widely known as a hard task for a precise discrimination $[20,21]$. The present study 
has shown that it is possible to distinguish the four species previously referred to by using characteristics of their female genitalia.

Regarding the epidemiological importance of Rodhnius species from Brazil, Gurgel-Gonçalves et al. [22] mentioned that $R$. nasutus and $R$. neglectus, for example, may overlap in geographic distribution in the northeastern Brazil. Then the external female genitalia can help specific distinction of Rhodnius spp that occupy the same area.

Given such observations, external female genitalia from 14 Rhodnius species were studied herein. This article also offers a key designed to contribute to the taxonomy of the group, and may later work for phylogenetic studies on this subfamily and genus.

\section{Methods}

Rhodnius brethesi $(\mathrm{N}=2), R$. colombiensis $(\mathrm{N}=5), R$. domesticus $(\mathrm{N}=7), R$. ecuadoriensis $(\mathrm{N}=2), R$. milesi $(\mathrm{N}=3), R$. montenegrensis $(\mathrm{N}=7), R$. nasutus $(\mathrm{N}=4), R$. neglectus $(\mathrm{N}=25) R$. neivai $(\mathrm{N}=2), R$. pallescens $(\mathrm{N}=2)$, $R$. pictipes $(\mathrm{N}=3), R$. prolixus $(\mathrm{N}=15), R$. robustus $(\mathrm{N}=7)$ and $R$. stali $(\mathrm{N}=3)$ were examined by SEM for this study.

These specimens were deposited or maintained in colonies at the Insetário de Triatominae da Faculdade de Ciências Farmacêuticas, Universidade Estadual Paulista (UNESP) - Araraquara and Laboratório Nacional e Internacional de Referência em Taxonomia de Triatomíneos/ FIOCRUZ/Rio de Janeiro. They were killed and cut transversely at the beginning of the abdomen. They were then washed, dehydrated using an alcohol-based compound, and ovendried at $50^{\circ} \mathrm{C}$. Next, they were fixed on aluminum supports at the fifth abdominal segment such that the posterior portion was at a 90-degree angle with the support base. Next, metal sputtering was used for 80 seconds at $10 \mathrm{~mA}$. Thereafter, the dorsal, ventral and posterior sides were examined using a Topcon SM 300 scanning electron microscope, Topcon corporation, Hasunumacho, Tokyo Itabashi-ku, Japan. The comparative study was performed using images from 87 samples.

Origins for the samples are shown in Tables 1 and 2 summarizes the different characteristics between the 14 Rhodnius species. All features herein described as differential characteristics were checked for at least 15 (except for $R$. ecuadoriensis (2), $R$. milesi (3) and $R$. neivai (2)) insects per species by light microscopy $(\mathrm{OM})$ to evaluate if there was intraspecific variability. Characteristics with interspecific variability were discarded from the description.

\section{Results}

The dorsal, posterior, and ventral sides of the 14 Rhodnius species were analyzed using SEM.

Evaluating the images for the Rhodnius species' dorsal sides aided in defining three primary characteristics:
1) The line that divides the seventh and eighth segments;

2) The shape of the ninth segment; and

3) The shape of the tenth segment.

After visualization of the posterior side Rhodnius species showed four primary characteristics:

1) The line that divides the eighth and ninth segments;

2) The line that divides the ninth and tenth segments;

3) The shape of the ninth segment; and

4) The shape of the tenth segment.

Examining the ventral side showed five primary characteristics:

1) The line that divides the seventh segment and the eighth gonocoxites and gonapophyses;

2) The shape of the eighth gonocoxites;

3) The shape of the eighth gonapophyses;

4) The shape of the ninth segment; and

5) The shape of the tenth segment.

Based on the characteristics presented by the line that divides the seventh and eighth segments in the dorsal perspective, the species were categorized into three groups:

a) Species with a curved dividing line: $R$. domesticus, $R$. ecuadoriensis, $R$. milesi, $R$. nasutus, $R$. neivai, $R$. pictipes, $R$. prolixus and $R$. stali (Figure $1 \mathrm{~A}-\mathrm{H}$ );

b) Species with a straight dividing line between the seventh and eighth segments: $R$. montenegrensis and $R$. robustus (Figure $1 \mathrm{I}, \mathrm{J}$ ); and

c) Species with a curved dividing line and an additional downward curve in the middle: $R$. brethesi, $R$. colombiensis, $R$. neglectus and $R$. pallescens (Figure $1 \mathrm{~K}-\mathrm{N}$ ).

Based on these criteria, a key was developed to identify the 14 Rhodnius species, which are described below.

I) The eight species in group $\boldsymbol{a}$ were separated by traits observed on the posterior and ventral sides; the results are as follows. The posterior perspective showed that $R$. domesticus has a moon-shaped line that divides the ninth and tenth segments (Figure 2A). The ventral perspective showed that the ninth segment ends slightly below the tenth segment (Figure 3A).

Rhodnius milesi has lateral transverse $1+1$ slits on the line that divides the ninth and tenth segments (Figure 2C). The ventral perspective showed that the ninth and tenth segments (Figure $3 \mathrm{C}$ ) end on the same plane.

R. ecuadoriensis does not include slits on the tenth posterior segment (Figure 2B). The ventral 


\begin{tabular}{|c|c|c|c|}
\hline Species & Colony & Origin & Initiated \\
\hline \multirow[t]{2}{*}{ R. brethesi } & 222 & Igarapé Tucunaré, Rio Curiduri, Barcelos, & $20 / 07 / 2009$ \\
\hline & & AM, Brazil & \\
\hline R. colombiensis & 050 & Tolima, Colômbia & 15/02/2001 \\
\hline R. domesticus & & Instituto René Rachou, Belo Horizonte, MG, Brazil & \\
\hline R. ecuadoriensis & & Laboratório Nacional e Internacional de Referência em Taxonomia de Triatomíneos, RJ, Brazil & \\
\hline R. milesi & & Belém, PA, Brazil & \\
\hline R. montenegrensis & 088 & Montenegro, RO, Brazil & 29/09/2008 \\
\hline R. nasutus & 053 & Patú, Messias Targino e Almino Afonso, RN, Brazil & 23/05/1983 \\
\hline R. neglectus & & Laboratório Nacional e Internacional de Referência em Taxonomia de Triatomíneos, RJ, Brazil & \\
\hline R. neivai & & Laboratório Nacional e Internacional de Referência em Taxonomia de Triatomíneos, RJ, Brazil & \\
\hline R. pallescens & 070 & Barro Colorado, Panamá & 14/12/1984 \\
\hline R. pictipes & 071 & Jacundá, PA, Brazil & 23/05/1983 \\
\hline R. prolixus & 074 & Venezuela & 25/05/1983 \\
\hline R. prolixus & 075 & Instituto Nacional de Salud, Bogotá, Colômbia & 15/12/1976 \\
\hline R. prolixus & 079 & Ortiz Caseiro, Edoguarica, Venezuela & 05/09/1999 \\
\hline R. robustus & & Laboratório Nacional e Internacional de Referência em Taxonomia de Triatomíneos, RJ, Brazil & \\
\hline R. robustus & 083 & Instituto de Medicina Tropical - Peru & $30 / 08 / 1973$ \\
\hline R. stali & & Laboratório Nacional e Internacional de Referência em Taxonomia de Triatomíneos, RJ, Brazil & \\
\hline
\end{tabular}

perspective showed that eighth gonocoxites ends projected to the ninth segment (Figure 3B).

The tenth segment of $R$. neivai is clearly separated into two lobes by a central slit in the posterior portion (Figure 2E). The ventral perspective showed that the eighth gonocoxites and gonapophyses have a V-shaped depression in the middle, and the tenth segment includes a slit in the middle (Figure 3E).

Rhodnius nasutus has $1+1$ lateral slits along the posterior end of the tenth segment (Figure 2D). The ventral perspective showed that the tenth segment is semi- circular in shape (Figure 3D).

The posterior perspective showed that the tenth segments in Rhodnius pictipes and $R$. stali are rectangular. In $R$. pictipes, a slit was observed at the dividing line between the ninth and tenth segments (Figure 2F). R. stali did not include this slit (Figure 2H). The ventral perspective showed that $R$. pictipes includes a ninth segment with wide lateral edges (Figure 1F, 3F), while in $R$. stali, these edges are narrow (Figure $1 \mathrm{H}, 3 \mathrm{H}$ ). The posterior perspective for Rhodnius prolixus showed that the line dividing the ninth and tenth segments is circular (Figure $2 \mathrm{G}$ ). On the ventral side, the posterior $1+1$ edges for the ninth segment are curved (Figure 3G).

II) The two species that compose group $\boldsymbol{b}$ were separated by traits observed in the dorsal, posterior and ventral portion.

The dorsal perspective showed that the seventh segment for $R$. montenegrensis forms $1+1$ lateral triangular points along the edge of the eighth segment, and the eighth segment is trapezoidshaped (Figure 1I). In $R$. robustus, the triangular points are smaller, and the eighth segment is rectangular (Figure 1J). From a posterior perspective, it is easier to distinguish between the ninth segment, which is longer in $R$. robustus than $R$. montenegrensis (Figure 2I,J). The ventral perspective showed that the dividing line between the seventh segment and eighth gonocoxites is circular in $R$. montenegrensis and curved in the middle of $R$. robustus (Figure 3I,J).

III) The four species in group $c$ were distinguished by traits on the posterior and ventral sides. The posterior perspective showed that $R$. pallescens includes an oval dividing line between the ninth and tenth segments (Figure $2 \mathrm{~N}$ ). 


\section{Table 2 Main characteristics found in the dorsal, posterior, and ventral views of the external female genitalia of 14 Rhodnius species}

\begin{tabular}{|c|c|c|c|}
\hline Species & Dorsal view & Posterior view & Ventral view \\
\hline R. domesticus & Curved line between 7th and 8th segments (Figure 1A) & $\begin{array}{l}\text { Moon-shaped line between the 9th and 10th } \\
\text { segments (Figure 2A) }\end{array}$ & $\begin{array}{l}\text { 9th segment ends slightly below the tenth } \\
\text { segment (Figure 3A). }\end{array}$ \\
\hline R. ecuadoriensis & Curved line between 7th and 8th segments (Figure 1B) & $\begin{array}{l}\text { No transverse } 1+1 \text { slits on the line between 9th and 10th } \\
\text { segments (Figure 2B) }\end{array}$ & $\begin{array}{l}\text { Points of 8th gonocoxite projected onto the 9th } \\
\text { segment (Figure 3B) }\end{array}$ \\
\hline R. milesi & Curved line between 7th and 8th segments (Figure 1C) & $\begin{array}{l}\text { Transverse } 1+1 \text { slits on the line between 9th and 10th } \\
\text { segments (Figure 2C) }\end{array}$ & $\begin{array}{l}\text { 9th and 10th segments finish at the same } \\
\text { plane (Figure 3C). }\end{array}$ \\
\hline R. nasutus & Curved line between 7th and 8th segments (Figure 1D) & $\begin{array}{l}\text { Transverse } 1+1 \text { slits on the line between the 9th and 10th } \\
\text { segments (Figure 2D) }\end{array}$ & Semi-circular 10th segment (Figure 3D) \\
\hline R. neivai & Curved line between 7th and 8th segments (Figure 1E) & 10th segment separated by a slit in $1+1$ lobes (Figure 2E). & $\begin{array}{l}\text { 7th segment line with V-shaped depression; } \\
\text { 10th segment with slit (Figure } 3 \mathrm{E}) \text {. }\end{array}$ \\
\hline R. pictipes & Curved line between 7th and 8th segments (Figure 1F) & $\begin{array}{l}\text { Rectangular 10th with a slit between 9th and 10th } \\
\text { segments (Figure 2F) }\end{array}$ & 9th segment with wide $1+1$ lateral edges (Figure 3F) \\
\hline R. prolixus & Curved line between 7th and 8th segments (Figure 1G) & Circular line between 9th and 10th segments (Figure 2G). & $\begin{array}{l}\text { Curved } 1+1 \text { posterior edges of the 9th } \\
\text { segment (Figure } 3 \mathrm{G}) \text {. }\end{array}$ \\
\hline R. stali & Curved line between 7th and 8th segments (Figure $1 \mathrm{H}$ ) & $\begin{array}{l}\text { Rectangular 10th segment with no slit in the } \\
\text { middle (Figure } 2 \mathrm{H} \text { ) }\end{array}$ & $\begin{array}{l}\text { 9th segment with narrow } 1+1 \text { lateral } \\
\text { edges (Figure } 3 \mathrm{H} \text { ) }\end{array}$ \\
\hline R. montenegrensis & $\begin{array}{l}\text { Straight line between } 7 \text { th and 8th with } 1+1 \text { triangular } \\
\text { points, and a trapezoidal shaped 8th segment (Figure } 11 \text { ) }\end{array}$ & Short 9th segment (Figure 2l) & $\begin{array}{l}\text { Circular line between 7th segment and 8th } \\
\text { gonocoxites (Figure 31) }\end{array}$ \\
\hline R. robustus & $\begin{array}{l}\text { Straight line between } 7 \text { th and 8th with small triangular } \\
\text { points and rectangular shaped 8th segment (Figure } 1 \mathrm{~J} \text { ). }\end{array}$ & Long 9th segment (Figure 2J) & $\begin{array}{l}\text { Line between 7th segment and the 8th gonocoxites } \\
\text { curved in middle (Figure } 3 \mathrm{~J} \text { ) }\end{array}$ \\
\hline R. brethesi & $\begin{array}{l}\text { Line between } 7 \text { th and } 8 \text { th segments that is slightly } \\
\text { curved in middle (Figure } 1 \mathrm{~K} \text { ) }\end{array}$ & 10th segment separated into $1+1$ lobes by a cavity (Figure 2K) & $\begin{array}{l}\text { 8th gonocoxites are separated from 8th } \\
\text { gonapophyses (Figure 3K) }\end{array}$ \\
\hline R. colombiensis & $\begin{array}{l}\text { Line between } 7 \text { th and 8th segments that is slightly } \\
\text { curved in middle (Figure } 1 \mathrm{~L} \text { ) }\end{array}$ & $\begin{array}{l}2+2 \text { appendages along line between the 8th and 9th } \\
\text { segments (Figure } 2 \mathrm{~L} \text { ) }\end{array}$ & $\begin{array}{l}\text { 8th gonocoxites are not separated from 8th } \\
\text { gonapophyses (Figure } 3 \mathrm{~L} \text { ). }\end{array}$ \\
\hline R. neglectus & $\begin{array}{l}\text { Line between } 7 \text { th and 8th segments that is slightly } \\
\text { curved in middle (Figure } 1 \mathrm{M} \text { ) }\end{array}$ & $\begin{array}{l}\text { Line between 9th and 10th segments that is oval shaped in } \\
\text { the anterior portion and which widens on the sides (Figure 2M) }\end{array}$ & $\begin{array}{l}\text { Line of } 7 \text { th segment is curved on the sides, but not } \\
\text { in the middle (Figure 3M). }\end{array}$ \\
\hline R. pallescens & $\begin{array}{l}\text { Line between } 7 \text { th and } 8 \text { th segments that is slightly } \\
\text { curved in middle (Figure } 1 \mathrm{~N} \text { ) }\end{array}$ & $\begin{array}{l}\text { Oval shaped line between the 9th and 10th } \\
\text { segments (Figure 2N) }\end{array}$ & $\begin{array}{l}\text { Line of } 7 \text { th segment has } 1+1 \text { curves on the sides } \\
\text { and is elevated in the middle (Figure } 3 \mathrm{~N} \text { ) }\end{array}$ \\
\hline
\end{tabular}




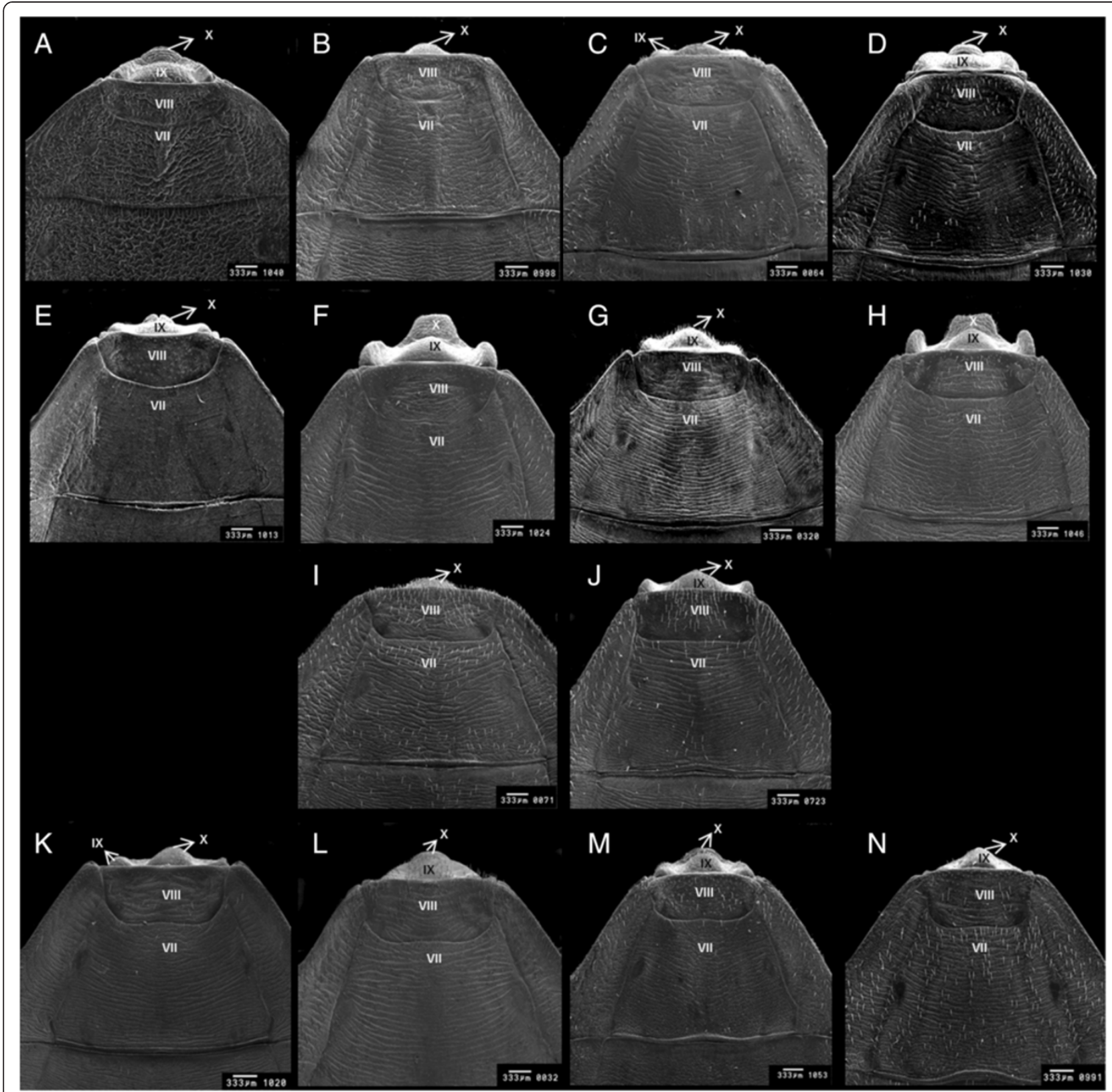

Figure 1 Female external genitalia of fourteen species of Rhodnius by scanning electron microscopy, dorsal side. A: Rhodnius domesticus; B: Rhodnius ecuadoriensis; C: Rhodnius milesi; D: Rhodnius nasutus; E: Rhodnius neivai; F: Rhodnius pictipes; G: Rhodnius prolixus; H: Rhodnius stali; I: Rhodnius montenegrensis; J: Rhodnius robustus; $\mathbf{K}$ : Rhodnius brethesi; L: Rhodnius colombiensis; $\mathbf{M}$ : Rhodnius neglectus and $\mathbf{N}$ : Rhodnius pallescens; VII, VIII, tergites; IX and X segments.

In $R$. neglectus, this line is also oval-shaped at the beginning, but it widens on the posterior sides (Figure 2M). The ventral perspective showed that R. pallescens has a dividing line between the seventh segment and eighth gonocoxites with $1+1$ lateral curves and a pronounced middle elevation (Figure $3 \mathrm{~N}$ ). Rhodnius neglectus includes the same lateral curves but not the middle elevation (Figure 3M).
The posterior perspective showed that the tenth segment of Rhodnius brethesi is separated into $1+1$ lobes by a cavity (Figure $2 \mathrm{~K}$ ), while $R$. colombiensis has $2+2$ appendages along the dividing line between the eighth and ninth segments (Figure 2L). The ventral perspective showed that $R$. brethesi includes eight gonocoxites that are separate from the eighth gonapophyses (Figure 3K). This separation was not observed in R. colombiensis (Figure 3L). 


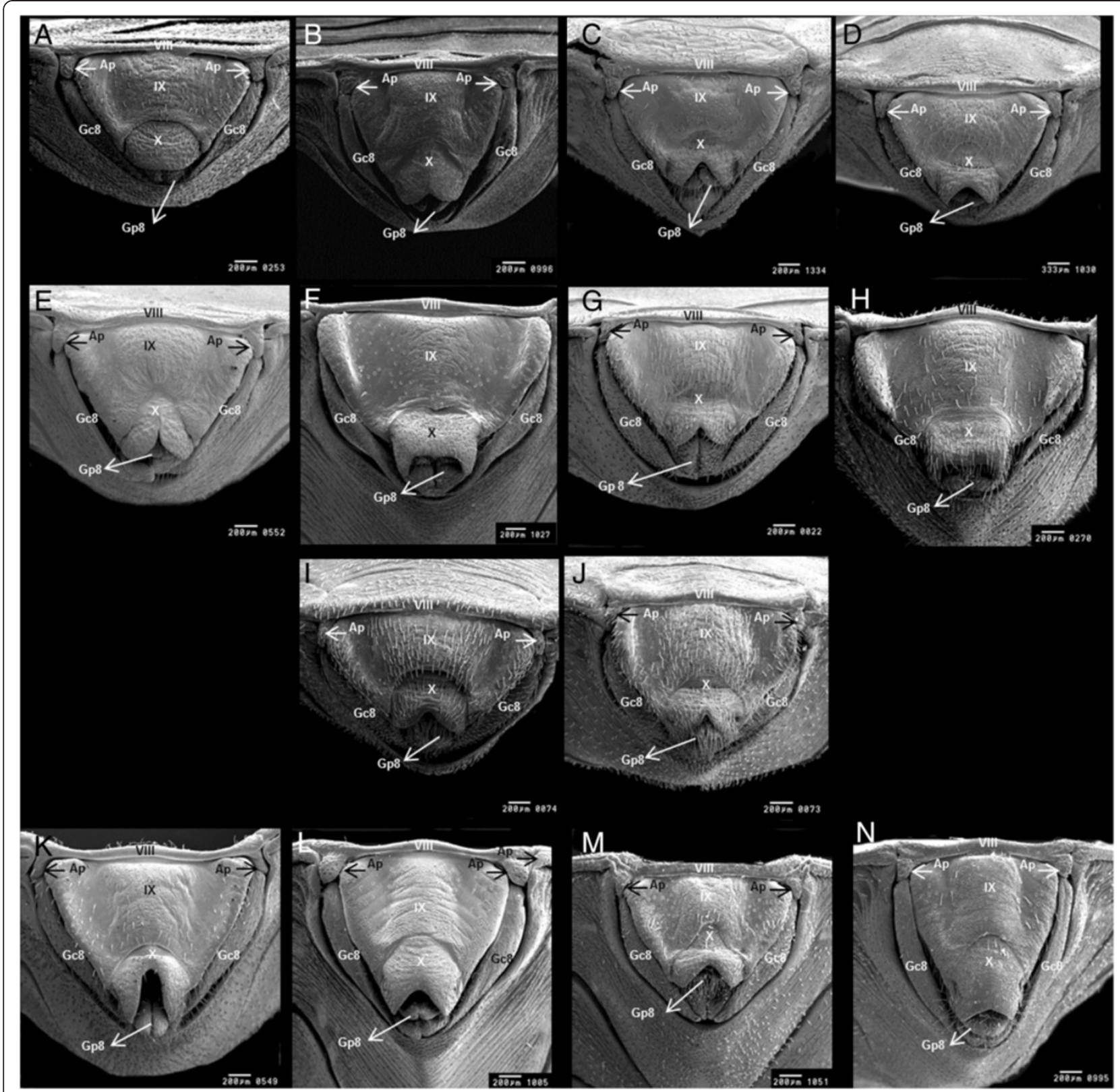

Figure 2 Female external genitalia of fourteen species of Rhodnius by scanning electron microscopy, posterior side. A: Rhodnius domesticus; B: Rhodnius ecuadoriensis; C: Rhodnius milesi; D: Rhodnius nasutus; E: Rhodnius neivai; $\mathbf{F}$ : Rhodnius pictipes; G: Rhodnius prolixus; $\mathbf{H}$ : Rhodnius stali; I: Rhodnius montenegrensis; J: Rhodnius robustus; K: Rhodnius brethesi; L: Rhodnius colombiensis; $\mathbf{M}$ : Rhodnius neglectus and $\mathbf{N}$ : Rhodnius pallescens; Ap: appendice; Gc8: gonocoxite 8; Gc9: gonocoxite 9; Gp8: gonapophyse 8; Gp9 gonapophyse 9; VIII tergite; IX and X segments.

The dorsal and ventral side cuticles for the Rhodnius species studied had transverse linear grooves, except for the $R$. domesticus cuticle, which comprised irregular grooves (Figure 1A).

\section{Discussion}

Even though female genitalia structures can be observed by OM, SEM has several advantages over optical. For this purpose it was possible to view the three dimensional external shape of a structure (in this case the female genitalia) in the same image. Electron microscopy also allows us to focus on many details of the structure. After checking them by OM, observations described the species specific features, and discarded the polymorphic ones.

Among the 18 Rhodnius species [2,12,13], the female external genitalia for $R$. amazonicus, $R$. dalessandroi, $R$. paraensis and $R$. zeledoni were not studied because specimens were unavailable. 


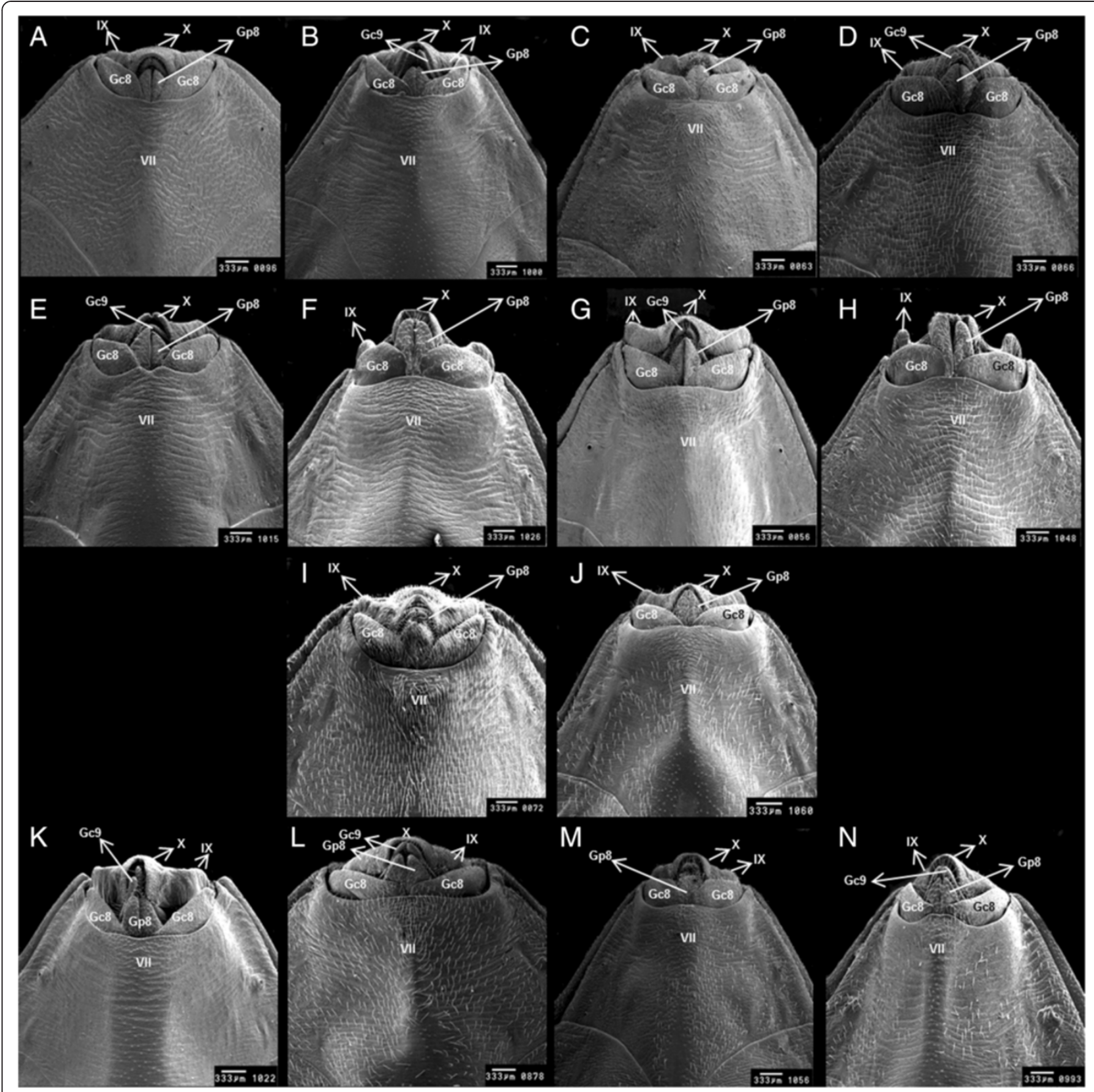

Figure 3 Female external genitalia of fourteen species of Rhodnius by scanning electron microscopy, ventral side. A: Rhodnius domesticus; B: Rhodnius ecuadoriensis; C: Rhodnius milesi; D: Rhodnius nasutus; E: Rhodnius neival; F: Rhodnius pictipes; G: Rhodnius prolixus; $\mathbf{H}$ : Rhodnius stall; I: Rhodnius montenegrensis; J: Rhodnius robustus; K: Rhodnius brethesi; L: Rhodnius colombiensis; M: Rhodnius neglectus and $\mathbf{N}$ : Rhodnius pallescens; Gc8: gonocoxite 8; Gc9: gonocoxite 9; Gp8: gonapophyse 8; Gp9 gonapophyse 9; VII sternite; IX and X segments.

The relevance of the male genitalia in specific identification of triatomines has beeen widely used by many authors, including Lent and Jurberg [18] to describe new species. On the other hand the female genitalia, also evaluated by other authors $[6,9]$, has shown itself less valuable due to the hard task of the dissection technique, unlike the male genitalia. The first publication in 2010 using SEM involving non-dissected insects of non-closely related triatomine species (P. megistus, P. herreri, $R$. prolixus, R. colombiensis, T. infestans and $T$. vitticeps), clearly showed that these species can be distinguished by this features [19]. However, in 2012 the validity of this approach was confirmed for closely related species ( $R$. robustus and $R$. montenegrensis) [13]. In an unpublished masters thesis, Simone Caldas Neves used the 
same approach to distinguish a recently described species (T. jatai [23], in the theses called T. n.sp.) closely related to T. costalimai [24].

Given the difficulties for specific distinctions in the Rhodnius species $[4,9,12]$ this study was performed to increase the number of morphological traits that can be used to identify the species in this genus.

For this study, details previously published for external female genitalia traits in four species were reconsidered; the species included were $R$. colombiensis, $R$. prolixus [19], $R$. montenegrensis and $R$. robustus [13].

The key presented and summarized in Table 2 was developed using the most evident traits to identify the 14 Rhodnius species using the external female genitalia. Three groups of species $(\boldsymbol{a}, \boldsymbol{b}$, and $\boldsymbol{c}$ ) were formed according to characteristics of the dividing line between the seventh and eighth dorsal segments, which is a visible and perceptible feature (Figure 1A-N). However, given the information verified by the 42 figures, the 14 species can be identified using traits on the dorsal, posterior, and ventral sides as either isolated or associated characteristics.

In the key, $R$. montenegrensis and $R$. robustus separation is based on the dorsal, posterior, and ventral sides (Figures 1I,J, 2I,J, 3I, and J). Though eight species from group $\boldsymbol{a}$ and four species from group $\boldsymbol{c}$ were characterized based on their posterior and ventral sides, it is important to note that these species also include characteristics on the dorsal side, as with $R$. nasutus and $R$. neivai, which have distinct tenth segment shapes (Figure 1D,E).

Thus, the dorsal side shows that the eighth, ninth and tenth segments are also distinct among the 14 species evaluated (Figure 1A-N).

Based on a posterior perspective, the 14 species can be distinguished by the dimension and shape of the eighth gonocoxites and gonapophyses, the ninth and tenth segments as well as the dividing lines between the eighth and ninth as well as the ninth and tenth segments. This perspective shows that the posterior portion of the tenth segment is concave at the end in 11 species (Figure 2B-E,G,I-N); in $R$. pictipes and $R$. stali, this segment is straight at the end (Figure 2F,H), while in $R$. domesticus, it is semi- circular (Figure 2A).

A ventral perspective shows that the 14 species have distinctive lines at the end of the seventh segment as well as shapes and dimensions for the gonapophyses, the gonocoxites, as well as the ninth and tenth segments. From this perspective, 10 species have a dividing line between the seventh segment and eighth gonocoxites as well as gonapophyses, which is curved at the sides and convex in the middle (Figure $3 \mathrm{C}-\mathrm{H}, \mathrm{J}, \mathrm{L}-\mathrm{N}$ ). In the remaining four species, this line is curved (Figure 3A,B,J, and $\mathrm{K})$. In six species, the eighth gonocoxites meet in a triangular shape (Figure 3A,B,G, and I-K); in the other eight species, this point is non-triangular (Figure $3 \mathrm{C}-\mathrm{F}, \mathrm{H}$, and
$\mathrm{L}-\mathrm{N})$. The eighth gonapophyses are triangular in 12 species (Figure 3A,E,G, and I-N) and rod-shaped in two species (Figure $3 \mathrm{~F}, \mathrm{H}$ ).

After combining the results herein on the external female genitalia for these 14 Rhodnius species using the five complexes established by Carcavallo et al. [20] for this genus, the following factors can be considered.

A comparative analysis of the external female genitalia characteristics for the $R$. dalessandroi complex was impossible because only $R$. milesi specimens were examined.

Rhodnius pictipes and R. stali, which compose the $R$. pictipes complex, include traits that join and exclude similar species. These traits include a dividing line between the seventh and eighth segments from the dorsal perspective, rectangular shape of the tenth segment from the posterior perspective, as well as ninth and tenth segment features (Figures 1F,H, 2F, and $\mathrm{H}$ ). From the ventral perspective, similarities were observed for the line that divides the seventh segment from the eighth gonocoxites and gonapophyses as well as the shape of the eighth gonocoxites and tenth segments (Figures $1 \mathrm{~F}, \mathrm{H}$, $2 \mathrm{~F}, \mathrm{H}, 3 \mathrm{~F}$, and $\mathrm{H})$. However, each of these two species maintained distinguishing characteristics. From the dorsal perspective at the intersection between the lines that separate the seventh segment and connectives, $R$. pictipes include $1+1$ triangles that are not evident in $R$. stali. The dorsal perspective also shows that $R$. stali comprise salient and straight lateral $1+1$ edges on the ninth segment, while in $R$. pictipes, these edges are wide (Figure 1F,H). From the ventral perspective, this difference is clarified by the shape of the ninth segment end portion, which is wide in $R$. pictipes and straight in $R$. stali (Figure 3F,H.)

For the $R$. prolixus complex, which comprises $R$. prolixus, $R$. domesticus, $R$. nasutus, $R$. neglectus, $R$. robustus, and, more recently, $R$. montenegrensis, the analyses confirmed that the connecting traits include the shape of the ventral line that divides the seventh segment from the eighth gonocoxites and gonapophyses, except for $R$. montenegrensis. The species include distinguishing traits on the three sides studied. A distinct trait was verified for $R$. domesticus, which was the only species of the 14 that does not include transversely grooved cuticles (Figure 1A). Importantly, $R$. neglectus and $R$. prolixus, which are particularly difficult to distinguish, do have distinguishing characteristics on the dorsal side; the line that separates the seventh and eighth segments is completely curved in $R$. prolixus, while in $R$. neglectus, it is curved on the sides and lightly convex in the middle (Figure 1G,M). On the posterior side, the difference between these two species evident through the dividing line between the ninth and tenth segments, which is circular in $R$. prolixus and oval at the beginning in $R$. neglectus but widens on the posterior sides (Figure 2G,M). The ventral side of $R$, prolixus 
shows a laterally expanded ninth segment, which was not observed in $R$. neglectus (Figures 3G,M).

Rhodnius colombiensis, R. ecuadoriensis and R. pallescens, which comprise the $R$. pallescens complex, include a set of ninth and tenth segments on the posterior side that form an isosceles triangle (Figure 2B,L, and N). This configuration clearly connects these three species. The distinction between such species is particularly evident on the ventral side, where the posterior portion of the eighth gonocoxites and gonapophyses is projected on the ninth segment in $R$. ecuadoriensis; however, the gonocoxite is not projected in $R$. colombiensis. This structure has a different shape in the two species (Figure 3B,L). In $R$. pallescens, the dividing line that separates the seventh segment from the eighth gonocoxites and gonapophyses is elevated in the middle; the elongated shape of the ninth and tenth segments also distinguishes this species from $R$. colombiensis and $R$. ecuadoriensis (Figure 3N,L, and B).

The studies performed herein facilitate identification and descriptions for three distinguishing features on the dorsal side, four features on the posterior side and five features on the ventral side of the external female genitalia in the 14 Rhodnius species, which distinguish the species. Using such findings, a key was developed to aid in distinguishing the 14 Rhodnius species. There is no record in the literature for intraspecific polymorphism for the female genitalia; however, this characteristic has not been widely explored. Given that, we do not discard the possibility of intraspecific variation for field populations and some of the features elected shall be confirmed with a much larger sample of field material. Therefore, we consider the possibility of further adjustments in the key. On the other hand, all descriptive studies in the morphology field also have this limitation. For triatomines, morphological variations, not described before, were detected for Rhodnius nasutus in Ceara [25], and Triatoma rubrovaria in Rio Grande do Sul [26].

The morphological traits for the external female genitalia validate four of the five complexes proposed by Carcavallo et al. [20] for the genus Rhodnius. They also specifically distinguish the species in the complexes. The fifth complex proposed by Carcavallo et al. [20], which also includes the species $R$. milesi was impossible to evaluate due to a lack of $R$. dalessandroi specimens.

It is important to highlight that the results herein corroborate the observations in Rosa et al. [19], which considered these traits for P. herreri, P. megistus, $R$. colombiensis, $R$. prolixus, $T$. infestans and T. vitticeps and validated the taxonomy. However, the study herein is a continuation of the study on the posterior ventral abdominal segments for the female nymphs in the fifth nymphal stage from six Triatominae species in Rosa et al. [27], wherein specifically distinguishing characteristics were identified.
Finally, it will necessary to clarify whether the features of the female genitalia described by SEM may also be observed through $\mathrm{OM}$ by non-experts. In addition, given the possible polymorphism for field populations we recommend: (i) first using to the traditional classification and then (ii) make use of this study for the specific confirmation.

\section{Conclusions}

Examination by SEM of the dorsal, posterior and ventral surfaces of the female external genitalia of 14 species of Rhodnius enabled the identification.

Through OM was also possible to identify the 14 species of Rhodnius.

\section{Competing interests}

The authors declare that they have no competing interest.

\section{Authors' contributions}

Conceived the study: JAR. Selected the bugs: VJM, SG, DBC, JO, JDN and HP. Prepared samples: VJM, SG, DBC, JO, JDN and HP. Analysed data: JAR, CG and JMSB. Interpreted data: JAR, VJM, SG, DBC, JO, JDN, HP, MCP, MC, CG and JMSB. Wrote the manuscript: JAR, VJM, SG, DBC, JO, JDN, HP, MCP, MC, CG and JMSB. All authors read and approved the final version of the manuscript.

\section{Acknowledgements}

The authors would like to thank the Triatomine and Chagas Disease Epidemiology Laboratory and the René Rachou Research Center (CPQRR) in Fiocruz, Minas Gerais, Brazil, which supplied the $R$. domesticus specimens, as well as Dr. Sebastião Aldo da Silva Valente from Instituto Evandro Chagas, Belém, Pará, Brazil, who provided the R. milesi specimens.

\section{Financial support}

The CAPES organization (Ministry of Education, Brazilian Government, Brazil), process number 23038.005285/2011-12, and FAPESP (Sao Paulo Research Foundation, Sao Paulo, Brazil), process numbers 2010/20 333-6, 50 355-1, and 15 386-3.

\section{Author details}

${ }^{1}$ Departamento de Ciências Biológicas, Faculdade de Ciências Farmacêuticas, Universidade Estadual Paulista, Rodovia Araraquara-Jaú km 1, 14 801-902, Araraquara, SP, Brasil. ²Departamento de Físico-Química, Instituto de Química, Universidade Estadual Paulista, Av. Prof. Francisco Degni, 55, 14 800-060 Araraquara, SP, Brasil. ${ }^{3}$ Departamento de Biologia Animal, Instituto de Biologia, Universidade Estadual de Campinas, Campinas, SP, Brasil. ${ }^{4}$ Centro Universitário de Araraquara - UNIARA, Araraquara, SP, Brasil. ${ }^{5}$ Departamento de Entomologia, Instituto Oswaldo Cruz, Laboratório Nacional e Internacional de Referência em Taxonomia de Triatomíneos, Rio de Janeiro, RJ, Brasil.

${ }^{6}$ Departamento de Epidemiologia, Faculdade de Saúde Pública, Universidade de São Paulo, São Paulo, SP, Brasil.

Received: 25 September 2013 Accepted: 27 December 2013 Published: 9 January 2014

\section{References}

1. OMS: Reporte sobre la enfermedad de Chagas. Grupo de trabalho científico, 17-20 de abril de 2005. Argentina: Buenos Aires; 2007. Actualizado en julio de 2007. http://whqlibdoc.who.int/hq/2007/TDR_SWG_09_spa.pdf. Acess: dez, 30. 2013.

2. Galvão C, Carcavallo R, Rocha DS, Jurberg J: A checklist of the current valid species of the subfamily Triatominae Jeannel, 1919 (Hemiptera, Reduviidae) and their geographical distribution, with nomenclatural and taxonomic notes. Zootaxa 2003, 202:1-36.

3. Forero D, Weirauch C, Baena M: Synonymy of the reduviid (Hemiptera: Heteroptera) genus Torrealbaia (Triatominae) with Amphibolus 
(Harpactorinae), with notes on Amphibolus venator (Klug, 1830). Zootaxa 2004, 670:1-12.

4. Neiva A, Pinto C: Estado actual dos conhecimentos sobre o gênero Rhodnius Stål, com a descrição de uma nova espécie. Bras Med 1923, 37:20-24.

5. Lent $H$, Jurberg J, Galvão C: Rhodnius stali sp. $\mathrm{n}$., afim de Rhodnius pictipes Stål, 1872 (Hemiptera, Reduviidae, Triatominae). Mem Inst Oswaldo Cruz 1993, 88:605-614.

6. Bérenger JM, Pluot-Sigwalt D: Rhodnius amazonicus Almeida, Santos \& Sposina, 1973, Bona Species, Close to R. pictipes Stål, 1872 (Heteroptera, Reduviidae, Triatominae). Mem Inst Oswaldo Cruz 2002, 97(1):73-77.

7. Garcia ES, Castro DP, Figuiredo MB, Azambuja P: Parasite-mediated interactions within insect vector: Trypanosoma rangeli strategies. Parasite Vector 2012, 5:105-111.

8. Stål C: Monographie der gattung conorhinus und verwandten. BerlinerEnt Zeitschr 1859, 3:99-117.

9. Lent H, Wygodzinsky P: Revision of the triatominae (Hemiptera, Reduviidae) and their significance as vectors of Chagas' disease. Bull Am Mus Nat Hist 1979, 163:123-520.

10. Mejia JM, Galvão C, Jurberg J: Rhodnius colombiensis sp.n. da Colômbia, com quadros comparativos entre as estruturas fálicas do gênero Rhodnius Stal, 1859 (Hemiptera, Reduviidae, Triatominae). Entomol Vect 1999, 6(6):601-617

11. Valente VC, Valente SAS, Carcavallo RU, Rocha DS, Galvão C, Jurberg J: Considerações sobre uma nova espécie do gênero Rhodnius Stål, do Estado do Pará, Brasil (Hemiptera, Reduviidae, Triatominae). Entomol Vect 2001, 8:65-80

12. Jurberg J, Rocha DS, Galvão C: Rhodnius zeledoni sp. nov. afim de Rhodnius paraensis Sherlock, Guitton \& Miles, 1977 (Hemiptera, Reduviidae, Triatominae). Biota Neotropica 2009, 9(1):123-128.

13. Rosa JA, Rocha CS, Gardim S, Pinto MC, Mendonça VJ, Ferreira Filho JCR, Carvalho EOC, Camargo LMA, Oliveira J, Nascimento JD, Cilense M, Almeida CE: Description of Rhodnius montenegrensis n. sp. (Hemiptera: Reduviidae: Triatominae) from the state of Rondônia, Brazil. Zootaxa 2012, 3478:62-76.

14. Naegele MP, Costa PI, Rosa JA: Polymorphism of the ITS-2 region of the ribosomal DNA of the Triatominae Rhodnius domesticus, $R$. pictipes, R. prolixus and R. stali. Med Vet Entomol 2006, 20:353-357.

15. Mendonça VJ, Silva MTA, Araújo RF, Martins J Jr, Bacci M Jr, Almeida CE, Costa J, Graminha MAS, Cicarelli RMB, Rosa JA: Phylogeny of Triatoma sherlocki (Hemiptera: Reduviidae: Triatominae) inferred from two mitochondrial genes suggests its location within the Triatoma brasiliensis complex. Am J Trop Med Hyg 2009, 81(5):858-864.

16. Gardim S, Rocha CS, Almeida CE, Takiya DM, Silva MTA, Ambrósio DL, Cicarelli RMB, Rosa JA: Evolutionary relationships of the Triatoma matogrossensis subcomplex, the endemic Triatoma in central-western Brazil, based on mitochondrial DNA sequences. Am J Trop Med Hyg 2013, 89(4):766-774

17. Almeida FB, Santos El, Sposina G: Triatomíneos da amazonia III. Acta Amazon 1973, 3(2):43-66.

18. Lent H, Jurberg J: O gênero Rhodnius stali, 1859, com um estudo sobre a genitália das espécies (Hemiptera, Reduviidae, Triatominae). Rev Bras Biol 1969, 29:487-560.

19. Rosa JA, Mendonça VJ, Rocha CS, Gardim S, Cilense M: Characterization of the external female genitalia of six species of Triatominae (Hemiptera: Reduviidade) by scanning electron microscopy. Mem Inst Oswaldo Cruz 2010, 105:286-292.

20. Carcavallo RU, Jurberg J, Lent H, Noireau F, Galvão C: Phylogeny of the Triatominae (Hemiptera: Reduviidae). Proposals for taxonomic arrangements. Entomol Vect 2000, 7(1):1-99.

21. Barata JMS: Aspectos morfológicos de ovos de Triatominae II-Características macroscópicas e exocoriais de dez espécies do gênero Rhodnius Stal, 1859 (Hemiptera, Reduviidae). Rev Saude Publica 1981, 15(5):490-542.

22. Gurgel-Gonçalves R, Galvão C, Costa J, Peterson AT: Geographic distribution of Chagas disease vectors in Brazil based on ecological niche modeling. J Trop Med 2012, 2012:1-15.

23. Gonçalves TCM, Teves-Neves SC, dos Santos-Mallet JR, Carbajal-de-la-Fuente AL, Lopes CM: Triatoma jatai sp. nov. in the state of Tocantins, Brazil (Hemiptera: Reduviidae: Triatominae). Mem Inst Oswaldo Cruz 2013, 108(4):429-437.

24. Teves-Neves SC: Análises morfológicas, morfométricas e moleculares revelam uma nova espécie do gênero Triatoma do Estado do Tocantins, Brasil. Instituto Oswaldo Cruz; 2012. http://arca.icict.fiocruz.br/handle/icict/6922. Access: nov 10. 2013.
25. Dias FBS, Paula AS, Belisário CJ, Lorenzo MG, Bezerra CM, Harry M, Diotaiuti L: Influence of the palm tree species on the variability of Rhodnius nasutus Stal, 1859 (Hemiptera, Reduviidae, Triatominae). Infect Genet Evol 2011, 11:869-877.

26. Almeida CE, Pacheco RS, Noireau F, Costa J: Triatoma rubrovaria (Blanchard, 1843) (Hemiptera: Reduviidae) I: isoenzymatic and chromatic patterns of five populations from the State of Rio Grande do Sul Brazil. Mem Inst Oswaldo Cruz 2002, 97(6):829-834.

27. Rosa JA, Barata JMS, Santos JLF, Belda Neto FM: Sexual distinction between 5th instar nymphs of six species of Triatominae (Hemiptera, Reduviidae). Mem Inst Oswaldo Cruz 1995, 87(2):257-264.

doi:10.1186/1756-3305-7-17

Cite this article as: da Rosa et al.: Study of the external female genitalia of 14 Rhodnius species (Hemiptera, Reduviidae, Triatominae) using scanning electron microscopy. Parasites \& Vectors 2014 7:17.

\section{Submit your next manuscript to BioMed Central and take full advantage of:}

- Convenient online submission

- Thorough peer review

- No space constraints or color figure charges

- Immediate publication on acceptance

- Inclusion in PubMed, CAS, Scopus and Google Scholar

- Research which is freely available for redistribution

Submit your manuscript at www.biomedcentral.com/submit
C) Biomed Central 